Résumés des conférences et travaux

\title{
Linguistique et philologie celtiques
}

\section{Pierre-Yves Lambert}

\section{OpenEdition \\ Journals}

Édition électronique

URL : https://journals.openedition.org/ashp/401

DOI : 10.4000/ashp.401

ISSN : 1969-6310

Éditeur

Publications de l'École Pratique des Hautes Études

\section{Édition imprimée}

Date de publication : 1 octobre 2008

Pagination : 364-365

ISSN : 0766-0677

Référence électronique

Pierre-Yves Lambert, "Linguistique et philologie celtiques », Annuaire de l'École pratique des hautes études (EPHE), Section des sciences historiques et philologiques [En ligne], 139 | 2008, mis en ligne le 04 décembre 2008, consulté le 12 juillet 2021. URL : http://journals.openedition.org/ashp/401 ; DOI : https://doi.org/10.4000/ashp.401 


\title{
LINGUISTIQUE ET PHILOLOGIE CELTIQUES
}

\author{
Directeur d'études : M. Pierre-Yves LAmberT, \\ correspondant de l'Institut
}

Programme de l'année 2006-2007: I. Vieil irlandais, le Bóroma, Histoire du tribut du Leinster. - II. Moyen gallois, extraits des textes de lois.

\section{Vieil irlandais, le Bóroma, Histoire du tribut du Leinster}

Le texte irlandais ancien intitulé Bóroma porte le nom d'un impôt en bétail (traditionnellement expliqué comme un composé des élements bó «bœuf» et rím « compte ») qui était prélevé chaque année sur le Leinster par le haut roi d'Irlande, le roi de Tara. Cette chronique, qui s'étend sur plus de cinq siècles, est une sorte de compilation, car presque tous les épisodes se retrouvent soit sous forme de légendes indépendantes, comme Cath Belaig Dún Bolaig, ou dans le cadre d'autres compilations : ainsi le premier épisode, l'établissement du tribut sous le règne de Tuathal Techtmar, se retrouve dans l'Acallam na Senórach, et le dernier épisode, la suppression du tribut obtenue par saint Moling à l'époque du roi Finnachta, se retrouve dans les « Fragmentary Annals ». C'est dans ce texte aussi qu'il est question de la mort triple du roi Loegaire : ayant juré par tous les éléments qu'il renonçait à prélever l'impôt, il se parjura et fut bientôt puni de ce parjure, par une mort triple.

On a suivi en partie l'édition de Wh. Stokes, $R C$ XIII, 1892, p. 32-124, et en partie l'édition diplomatique du manuscrit appelé «Livre de Leinster » ou « Livre de Noughaval », éd. R. I. Best, M. O'Brien, t. V, Dublin, 1967, p. 1268-1318 (où l'on trouve le texte entier des poèmes, le plus souvent omis dans l'édition Stokes).

\section{Moyen gallois, extraits des textes de lois}

On a continué de traduire quelques passages des textes de lois en moyen-gallois : des extraits de Llyfr Blegywryd (Dull Dyfed), notamment les dispositions relatives aux juges et aux procédures (Ll. Bleg. 15.1-18.21), ainsi que le début des triades; et des extraits de Llyfr Iorwerth, notamment la procédure relative aux contestations de propriété foncière, qui est présentée ici de façon très détaillée, avec les questions et les réponses échangées entre les parties et le juge (cf. Aled Rhys Wiliam, Llyfr Iorwerth, a critical edition of the Venedotian Code of Medieval Welsh law, Cardiff, Univ. of Wales Press, 1960 : § 72-81, procédure du hawl am dir a daear). Ce même code est notre source pour le serment du juge, appelé (§1) diofryd brawd - ce qui est généralement interprété comme « le vœu de renonciation (d'impartialité) de la fonction de juge ", mais c'est probablement inexact, car le juge se dit brawdwr, et brawd n'est pas sa fonction, mais sa décision, sa sentence. Il convient à mon avis de remonter un peu plus dans l'histoire du mot. En effet le correspondant irlandais ancien de brawd se 
rencontre parfois dans le sens de « vœu » dans l'expression bráth bennachtan « vœu de bénédiction "; on doit sans doute supposer un composé lâche, diofryd-frawd, où diofryd renvoie à l'idée de renonciation, renoncement, mise à l'écart (*di-au-bhr-to-, cf. v. irl. diupart *di-uss-bhr-ta « enlèvement, privation »), tandis que brawd a conservé ici un sens très ancien de «parole qui donne : promesse, vœu ». Sur ces deux mots, E. Hamp avait fourni des éclaircissements étymologiques («barnu, brawd», Celtica XI [1976], p. 68-75; sur diofryd, diefryd, cf. ZCP, XXXIX (1982), 212-214); le sens de bráth « vœu » fournit le meilleur moyen d'expliquer le gaulois $\beta \rho \alpha \tau o v$, dans les formules d'offrande des inscriptions gallo-grecques; c'est l'hypothèse que j'ai déjà for-

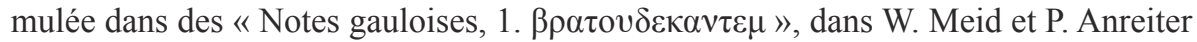
(éd.), Die grösseren altkeltischen Sprachdenkmäler, Innsbruck, 1996, p. 86-94.

Concernant les triades, on a mis l'accent sur la recherche des sources : on a recherché les correspondances possibles soit avec les lois irlandaises, soit avec les collections canoniques. Un exemple suffira : le premier élément d'une triade étrange des " trois quatre », petwar achaws yd ymchoelir brawt; o ofyn gwr kadarn, a chas galon, a charyat kyfeillon, a serch da, «quatre raisons par lesquelles un jugement est perverti, la crainte d'un puissant, la haine des ennemis, l'attachement aux amis, et l'appât du gain » Ll. Bleg. 109.5-8, se révèle être inspiré par un passage de la Collectio Canonum Hibernensis, Isidorus dicit; Quatuor modis judicium hominis pervertitur, timore, cupiditate, odio, amore... (Coll. Can. XXI.13 : Wasserschleben, p. 66) qui reprend Isidore, Sententiae III.54.7 et l'amplifie d'un cinquième modus. La version latine des Lois galloises semble être une rétroversion du gallois, ou bien une vague réminiscence de l'original latin : Quatuor de causis vertitur iudicium, scilicet amore, odio, precio, timoris maioris personae (H. Emanuel [éd.], The Latin Texts of the Welsh Laws, p. 244). Ainsi, ce n'est pas seulement le droit irlandais, mais aussi le droit gallois qui s'inspire des collections canoniques irlandaises, comme l'a montré Luned Davies dans Peritia, t. XII.

On a vu aussi des textes hors programme, comme les Englynion y Clyweit et des passages du mystère moyen-breton de sainte Nonne. M. Claude Lamoureux a eu l'obligeance de parler du fonctionnement du calendrier de Coligny. 